\title{
REVIEW
}

Open Access

\section{Factors associated with water consumption among children: a systematic review}

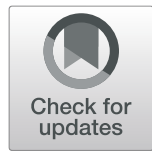

Carmen B. Franse ${ }^{1}$, L. Wang ${ }^{1}$, Florence Constant ${ }^{2}$, Lisa R. Fries ${ }^{3}$ and Hein Raat ${ }^{*}$ (I)

\begin{abstract}
Background: Water is recommended as the main beverage for daily fluid intake. Previous systematic reviews have studied the consumption of sugar-sweetened beverages (SSBS) among children, but none have focused on water consumption. Insight into factors that are associated with children's water intake is needed to inform the development of interventions aimed at the promotion of water consumption. The objective of this review was therefore to summarize the current evidence on factors associated with water consumption among children aged 2 to 12 years.

Methods: A systematic literature search in seven electronic databases was conducted in May, 2018 and retrieved 17,850 unique records. Two additional studies were identified by hand-searching references of included articles. Studies were selected if they had a cross-sectional or longitudinal study design, focused on children aged 2-12 years and published in an English language peer-reviewed journal. Participants from clinical populations, studies that included data of $<10$ participants and non-human studies were excluded.

Results: A total of 63 articles met inclusion criteria and were included in the analysis. We identified 76 factors that were investigated in these studies; 17/76 were investigated in a longitudinal study. There was evidence of positive associations between water consumption and child's self-efficacy, parental education level, parental self-efficacy, use of feeding practices such as restriction or encouraging healthy eating and study year. Evidence was inconsistent $(<60 \%$ of studies reported an association) for child's age, sex, BMI, consumption of SSBs and ethnic background of the parent. There was no evidence ( $\leq 33 \%$ of studies reported an association) of associations between consumption of milk or juice, parental emotional-, modelling- or instrumental feeding practices, eating school lunch or outside temperature and water consumption. The remaining 54 factors were investigated in fewer than three studies.
\end{abstract}

Conclusions: There is some evidence for an association between potentially modifiable parental and child-related factors and water consumption. However, most factors identified in this review were only studied by one or two studies and most studies were cross-sectional. More longitudinal research is necessary to investigate environmental, parental and child-related factors associated with water consumption that are currently under-studied and could further inform intervention strategies.

Trial registration: PROSPERO ID\# CRD42018093362, registered May 22, 2018.

Keywords: Water, Beverages, Children, Behavior, Systematic review

\footnotetext{
*Correspondence: h.raat@erasmusmc.nl

'Department of Public Health, Erasmus University Medical Center,

Wytemaweg 80, 3015, CN, Rotterdam, The Netherlands

Full list of author information is available at the end of the article
}

(c) The Author(s). 2019 Open Access This article is distributed under the terms of the Creative Commons Attribution 4.0 International License (http://creativecommons.org/licenses/by/4.0/), which permits unrestricted use, distribution, and reproduction in any medium, provided you give appropriate credit to the original author(s) and the source, provide a link to the Creative Commons license, and indicate if changes were made. The Creative Commons Public Domain Dedication waiver (http://creativecommons.org/publicdomain/zero/1.0/) applies to the data made available in this article, unless otherwise stated. 


\section{Background}

The rate of childhood obesity has increased dramatically in the past decades and remains a leading cause of public health concern, as overweight and obese children are at greater risk for diabetes, heart disease, and other health conditions [1-4]. In 2017, the number of overweight or obese children under the age of five was reported to be over 38 million worldwide [5]. The prevalence of overweight, including obesity, among school-aged children in the US is around 34\% [6] and in European countries between 18 to $57 \%$ [7]. As childhood obesity has been shown to track into adulthood $[8,9]$, it is critical to develop healthy eating and drinking habits early in life.

There are many different actions that have been recommended by leading public health organizations to fight the obesity epidemic [10-12], one of which involves limiting children's consumption of sugar sweetened beverages (SSBs). SSBs, such as soft drinks, fruit drinks and energy drinks, are currently one of the largest sources of added sugars among children [13, 14]. Greater consumption of SSBs has been associated with weight gain and obesity [15-17]. Several longitudinal studies have found that replacing SSBs with water or other non-caloric beverages slows the accumulation of body fat [18-20]. Zheng et al. who followed a cohort of 9 year old children found that daily replacement of $100 \mathrm{~g}$ of water for $100 \mathrm{~g}$ of SSBs was inversely associated with changes in BMI over 6 years [18]. Some randomizedcontrolled trials have been effective in both increasing water consumption and decreasing SSB consumption [21-23] or risk of overweight [24]. Adding to this, replacing SSBs with water could also reduce tooth decay as the consumption of SSBs is associated with dental caries in children and adults [25, 26]. In 2006, a guidance system for beverage consumption was developed in which water was recommended as the main beverage for daily fluid intake [27]. Since then, the American Academy of Pediatrics and the European Society for Paediatric Gastroenterology Hepatology and Nutrition have both stated that plain water should be promoted as the principal source of hydration for children and adolescents [28, 29]. However, in many countries, water makes up around half of children's beverage intake or less; in a multi-country study across three continents, this was the case for $11 / 13$ countries [30]. Nationally representative surveys have estimated water consumption to be 25 to $32 \%$ of total beverage intake among British children [31], 36 to $40 \%$ among US children [32], 38 to $40 \%$ among Mexican children [33], and 55 to $58 \%$ among French children [34]. In order to develop effective intervention strategies that promote water consumption among children, it is important to study which sub-populations could benefit most from these strategies and which modifiable factors these strategies could target. Currently, no overview exists on factors that are associated with water consumption among children. Previous systematic reviews have studied the factors influencing the consumption of SSBs among children [15, 16, 35], but none have focused on factors associated with water consumption.

The current review aims to identify and synthesize the evidence about the factors that influence children's water consumption, in order to make specific recommendations about how to design interventions that could promote this behavior [35]. The socio-ecological model was applied as a framework for the factors identified in our review. The socio-ecological model describes how factors can influence a behavior from a variety of levels, including the individual level (characteristics and behavior of the child), the interpersonal level (characteristics of and interaction with parents or others), and the environmental level (characteristics of and interaction with the home, school and community), as well as the interplay between these levels [36]. At the individual level, factors that are associated with children's food and beverage choices could be the child's age, sex and psychological factors such as self-efficacy; in this context, this would mean the child's confidence to be able to select healthy foods and drinks [37]. An important category of interpersonal factors are feeding practices, which are specific behaviors done by parents to influence what, when, or how much their child eats or drinks [38]; these have been shown to be associated with children's diet [39]. The availability and accessibility of foods and beverages in the home or classroom are examples of environmental factors that could be associated with food and beverage choice in children [40-42]. The purpose of this review was therefore to summarize the current evidence on the factors associated with water consumption among children aged 2 to 12 years.

\section{Methods \\ Search strategy}

A systematic literature search was conducted in May, 2018, using the following electronic databases: Embase, Medline Ovid, Web of Science, Cochrane, PsychINFO Ovid, CINAHL EBSCOhost, and Google Scholar. A combination of the following key words were included in the search: (water or beverage* or drink" or related key words) and (child" or infant" or toddler" or related key words) and (determinant" or factor" or life-style* or diet $^{*}$ or parental attitude* or related key words). The search strategy was adapted to each database. The complete search strategies used are presented in Additional file 1. In addition to database searching, the references of relevant articles were screened for other potentially relevant studies. We registered the systematic review protocol for this study in the PROSPERO registry 
under registration number CRD42018093362 on May 22, 2018.

\section{Selection process}

Duplicates of records retrieved in the search were removed. Title and abstract screening of the remaining records was performed by two independent researchers (CF and LW) to identify studies that met the inclusion criteria. Any disagreements at this stage were discussed between them and, if necessary, resolved by consultation with a third reviewer. Copies of full text articles were ordered for all relevant studies. Full text screening of articles was then performed by two independent researchers (CF and LW). Disagreements that arose at this stage were also resolved by consultation with a third reviewer.

\section{Inclusion and exclusion criteria}

The criteria for including studies for this review applied in the selection process were as follows: 1) participants were children with mean age between 2 and 12 years (pre-school and primary schools age) at baseline, we did not include children aged $0-2$ years because recommendations for and patterns of beverage intake change substantially over this age range (for breastmilk, water, types of milk, juice, etc.); 2) studies quantitatively assessed the association of any type of factor with water consumption, we considered factors both longitudinal determinants and cross-sectional correlates; 3) the following categories of water were included: tap water, bottled drinking water, unflavored sparkling water, flavored water (non-sugar sweetened) or any source of drinking water. Initially we included unsweetened tea without milk as a secondary outcome, however we did not find studies that measured this outcome; 4) studies had an observational design (longitudinal or cross-sectional); and 5) studies were published in an English language peer-reviewed journal, we did not limit the search to a specific time period and included all articles published since the inception of the journal. The main exclusion criteria were: 1) participants were from clinical populations (e.g. gastroenteritis, lung infections, malnutrition); 2) studies that included data of less than 10 participants; and 3) non-human studies.

\section{Risk of bias assessment}

The risk of bias of the included studies was assessed independently by two reviewers (CF and LW) using a version of the Risk Of Bias In Nonrandomized Studies of Interventions (ROBINS-I) assessment tool that has been adapted for use in observational studies [43, 44]. As recommended by the developers of the tool, the precise definitions of the levels for the bias domains within the protocol were adapted to the current study topic and research aims, to enable homogeneity in judgement of bias
(See Additional file 2). The following domains of bias were assessed: bias due to confounding, bias in the selection of participants into study, bias in classification of exposures, bias due to departures from intended exposures, bias due to missing data, bias in measurement of outcomes and bias in selection of the reported result. For each domain of bias, the study was categorized as having 'critical', 'serious', 'moderate', or 'low' risk of bias. For example, for the 'bias due to confounding' domain it was assessed whether confounding was to be expected in the association between the factor and water consumption and whether the study corrected for confounding variables, such as the child's sex and age. If it was not possible to determine the risk of bias for a certain bias domain due to missing information in the article, the domain was coded as 'no information'. More information on how each bias domain was categorized as having 'critical, 'serious', 'moderate', or 'low' risk of bias can be found in Additional file 2. The most serious rating across these bias domains determined the overall risk of bias; e.g. if a study was categorized as having a 'moderate' risk of bias in six domains but a 'serious' risk of bias in one domain, the overall risk of bias was serious. Discrepancies in the judgment of bias between the two reviewers were identified and resolved through discussion.

\section{Data extraction}

A standardized data extraction form was developed after discussion and consensus among the study team. This standardized form was used to extract data from the included studies by a researcher (CF or LW) and all data entered in the form was checked by one of the researchers (CF). Extracted information included: year and author of study, country, study design, population and characteristics, outcome, measurement instruments used, type and level (individual, interpersonal, environmental) of factor studied, and the association between correlate/determinant and outcome. For each factor, we qualitatively described the association between correlate/ determinant and water consumption (positive; negative; or no significant positive/negative association), see Additional file 3: Table S1. We considered quantitative measures of association reported in the studies such as correlation, cross-tabulation, analysis of variance and regression. When in a study analyses adjusted for confounding factors were reported, these were used. We identified three repeated cross-sectional studies and three longitudinal studies (see results section), the analyses that were used in these studies are described in Additional file 3: Table S1.

\section{Data synthesis}

To summarize the evidence on the association of a specific factor with water consumption among children, we 
used a previously established method [35, 45]. The number of studies that supported the association between a specific factor and water consumption was divided by the total number of studies that examined that factor. Factors investigated by three studies or less were coded as: no association (0) when $0-33 \%$ of studies found a significant association; inconsistent association (?) when $34-59 \%$ of studies found a significant association; positive $(+)$ or negative $(-)$ association when $60-100 \%$ of studies found a significant association. Factors investigated by four or more studies were coded as: no association (00) when $0-33 \%$ of studies found a significant association; inconsistent association (??) when $34-59 \%$ of studies found a significant association; positive $(++)$ or negative $(--)$ association when $60-100 \%$ of studies found a significant association.

\section{Results}

\section{Study selection}

The process of inclusion and exclusion of articles at each stage is described using the preferred reporting items of systematic reviews and meta-analyses (PRISMA) [46] flow chart (Fig. 1). A total of 33,410 records were identified after searching the seven databases. After removal of duplicates, 17,850 records remained. After all rounds of screening, 61 articles were identified. Two additional studies were identified by hand-searching the references of the included articles, resulting in a total of 63 articles that met the inclusion criteria and were included in the analysis.

\section{Study characteristics}

The characteristics of the studies included in this review are summarized in Table 1, and details of studies can be found in Additional file 3: Table S1. From the 63 included studies, 29 studies (46\%) were conducted in Europe [31, 34, 47-73] and 22 studies (35\%) were conducted in North America [32, 74-94]. One study was conducted in sites in Europe, South America and Asia [30] and the remaining 11 studies were conducted in South America [33, 95-98], Australia [99-101] or Asia [102-104]. Most studies (49/63; 78\%) were published in 2010 or later $[30-34,47-57,60-64,67-69,71,76,77$, $80-86,88-90,93,94,96-98,100-103]$, only 2 studies (3\%) were published before $2000[65,66]$. Almost all studies $(57 / 63 ; 90 \%)$ had a cross-sectional design [30-34, $47-55,57-69,72,74-76,78-99,101-104] ; 3$ studies had a repeated cross-sectional design [56, 73, 77], and 3 studies had a longitudinal design [70, 71, 100].

The most common measure of water consumption was a single day, 24-h recall (20 studies; $32 \%$ ) [33, 63, 65, 76-78, 81-84, 87, 89-92, 94, 95, 99, 100, 102], followed by Food Frequency Questionnaires (FFQ; 18 studies, 29\%) [48, 50, 52, 55, 57, 61, 62, 67, 68, 71, 72, $74,80,85,88,97,101,103]$, prospective dietary records (16 studies, 25\%) [30, 31, 34, 47, 49, 51, 53, 59, 60, 66, $69,70,73,75,96,98]$, multiple-day 24 -h recalls (6 studies, $10 \%)[32,54,64,79,93,104]$, and behavioral observation (3 studies, $5 \%$ ) [56, 58, 86].

Thirty studies $(48 \%)$ reported the amount of water consumed in volume per day [30-34, 47-50, 54, 58-60, $63,64,67-70,72,73,75,82,87,88,94-96,98,103], 21$

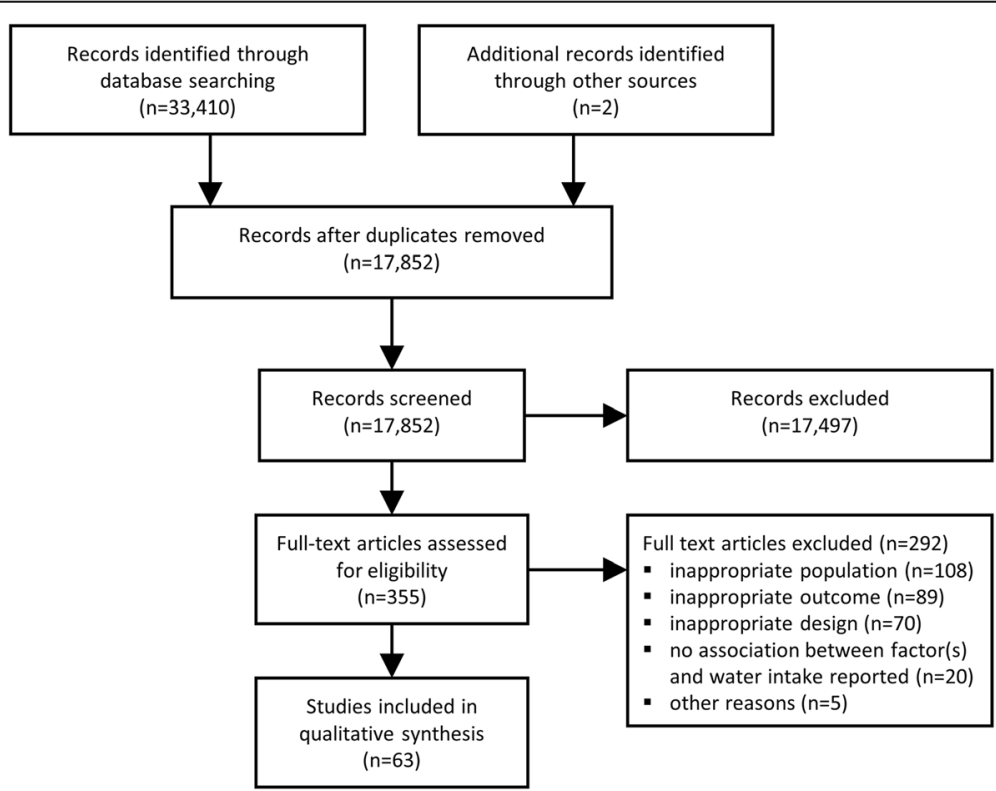

Fig. 1 Flow chart for the selection of reviewed studies 
Table 1 Characteristics of the studies included in the systematic review, $N=63$

\begin{tabular}{|c|c|}
\hline Characteristics & $\mathrm{N}$ of studies $(\%)$ \\
\hline \multicolumn{2}{|l|}{ Place study } \\
\hline Europe & $29(46)$ \\
\hline North America & $22(35)$ \\
\hline South America & $5(8)$ \\
\hline Australia & $3(5)$ \\
\hline Asia & $3(5)$ \\
\hline Europe, South America, Asia & $1(2)$ \\
\hline \multicolumn{2}{|l|}{ Year published } \\
\hline$\geq 2010$ & $49(78)$ \\
\hline 2000-2009 & $12(19)$ \\
\hline$<2000$ & $2(3)$ \\
\hline \multicolumn{2}{|l|}{ Design } \\
\hline Cross-sectional & $57(90)$ \\
\hline Repeated cross-sectional & $3(5)$ \\
\hline Longitudinal & $3(5)$ \\
\hline \multicolumn{2}{|l|}{ Number of participants } \\
\hline$<100$ & $2(3)$ \\
\hline 100-299 & $14(22)$ \\
\hline 300-999 & $17(27)$ \\
\hline$\geq 1000$ & $30(48)$ \\
\hline \multicolumn{2}{|l|}{ Age children } \\
\hline Preschool age ( $\pm 2-5$ years) & $16(25)$ \\
\hline School age ( $\pm 6-12$ years $)$ & $25(40)$ \\
\hline Both age groups & $22(35)$ \\
\hline \multicolumn{2}{|l|}{ Measure instrument water consumption } \\
\hline 1 day $24-\mathrm{h}$ recall & $20(32)$ \\
\hline Multi day 24-h recall & $6(10)$ \\
\hline Food Frequency Questionnaire & $18(29)$ \\
\hline Prospective dietary records & $16(25)$ \\
\hline Observation researcher & $3(5)$ \\
\hline \multicolumn{2}{|l|}{ Outcome water consumption } \\
\hline Water consumption in volume/day & $30(48)$ \\
\hline Water consumption in servings/day & $21(33)$ \\
\hline Any water consumption (yes/no) & $10(16)$ \\
\hline Water consumption in $\mathrm{ml} / \mathrm{kg}$ body weight/day & $2(3)$ \\
\hline
\end{tabular}

studies (33\%) measured water consumption in servings per day $[51,52,55,57,61,62,66,71,74,79$, 80, 83-85, 89, 91, 97, 99, 101, 102, 104], 10 studies (16\%) measured any water consumption (yes/no) [53, $56,65,77,78,81,86,90,93,100]$ and two studies measured water consumed in $\mathrm{ml}$ per kilo body weight per day [76, 92].

\section{Risk of bias}

The risk of bias in each study can be found in Additional file 3: Table S2. The overall risk of bias was classified as 'moderate' in 8/63 studies (13\%), 'serious' in 54/63 studies $(86 \%)$ and 'critical' in one study (2\%). The largest source of bias was due to the measurement of outcomes, with 41/63 studies (65\%) being classified as having 'serious' risk of bias in this domain, due to reliance on one day $24 \mathrm{~h}$ recalls or FFQs. Almost half of the studies $(29 / 63 ; 46 \%)$ were classified as having 'serious' risk of bias due to confounding because they did not correct for potential confounding factors, such as the child's sex and age. Potential bias due to missing data could not be determined for $45 / 63$ studies (71\%), due to the studies not reporting how much data was missing and/or differences between included and excluded participants. Risk of bias in the selection of participants into the study, in the classification of exposures and in the selection of the reported result was relatively low compared to the other bias domains (73, 88 and $84 \%$ of studies were classified as having a 'low' or 'moderate' risk of bias in these categories, respectively).

\section{Factors associated with water consumption in children}

Table 2 provides an overview of all factors associated with water consumption in children that were investigated in the 63 studies. Details of the associations can be found in Additional file 3: Table S1. Of the 76 factors identified, $55(72 \%)$ of the factors were investigated by one or two studies, $10(13 \%)$ of the factors were studied by 3 studies and $11(14 \%)$ of the factors were studied by 4 or more studies. Among the total of 76 factors, only 17 factors $(22 \%)$ were studied in a longitudinal study. Results are presented in the context of the socio-ecological framework, using the following categories: individual factors, interpersonal factors, and environmental factors.

\section{Individual factors}

Thirty individual level factors were identified, of which 22 factors were only studied in one or two studies. Four factors were studied in a longitudinal study. There was evidence for a positive association between the child's self-efficacy in consuming enough water and water consumption (3/3 studies; all cross-sectional). One crosssectional study found a positive association between consumption of fruit or vegetables and water consumption and one cross-sectional study found a negative association between consumption of sugar and water consumption. There was inconsistent evidence for positive associations between the child's age and water consumption (7/16 studies; 15 cross-sectional 1 longitudinal) and between the child's body mass index (BMI) and water consumption (3/8 studies; 7 cross-sectional 1 longitudinal). There was also inconsistent evidence for 
Table 2 Evidence of 63 included studies on the association between factors and water consumption among children

\begin{tabular}{|c|c|c|c|c|c|}
\hline Factor & Negative association & No association & Positive association & $n / N^{a}$ & Summary $^{b}$ \\
\hline \multicolumn{6}{|l|}{ Individual level } \\
\hline \multicolumn{6}{|l|}{ Socio-demographic } \\
\hline Age & Beltrán-Aguilar; Sohn & $\begin{array}{l}\text { Cockburn; Coppinger; } \\
\text { Fenandez-Alvira, 2014; Patel, } \\
\text { 2014; Petter; Vieux, 2017; } \\
\text { Wang }\end{array}$ & $\begin{array}{l}\text { Barraj; Drewnowski; } \\
\text { Feferbaum; Jomaa; Patel, } \\
\text { 2013; Piernas; Vieux, } 2016\end{array}$ & $7 / 16$ & $? ?$ \\
\hline Sex (girl) & $\begin{array}{l}\text { Jomaa; Lioret; Papandreou; } \\
\text { Patel, 2014; Pinket 2016b; } \\
\text { Piernas(4-8y)'; Vieux, } 2016\end{array}$ & $\begin{array}{l}\text { Beltrán-Aguilar; Bougatsas; } \\
\text { Campos; Coppinger; } \\
\text { Drewnowski; Fenandez-Alvira, } \\
\text { 2014; Piernas }(9-13 y)^{c} \text {; Sichieri; } \\
\text { Sohn; Vieux, 2017; Zohouri }\end{array}$ & Cockburn & $8 / 19$ & $? ?$ \\
\hline \multicolumn{6}{|l|}{ Health } \\
\hline BMl & & $\begin{array}{l}\text { Dodd; Jomaa; Maffeis; Sichieri; } \\
\text { Vieux, } 2017\end{array}$ & $\begin{array}{l}\text { Cardon; Papandreou; } \\
\text { Sleddens }\end{array}$ & $3 / 8$ & $? ?$ \\
\hline Medical condition & & Cockburn & & $0 / 1$ & 0 \\
\hline \multicolumn{6}{|l|}{ Psychosocial } \\
\hline Knowledge & & & Murnan & $1 / 1$ & + \\
\hline Expectations of drinking water & & & Sharma & $1 / 1$ & + \\
\hline Desire to drink any beverage & & Lora & & $0 / 1$ & 0 \\
\hline Intention to drink water & & & Patel, 2014 & $1 / 1$ & + \\
\hline Preference water & & & Cullen & $1 / 1$ & + \\
\hline $\begin{array}{l}\text { Preference sugar-sweetened } \\
\text { beverages }\end{array}$ & & Cullen & & $0 / 1$ & 0 \\
\hline Self-efficacy drinking water & & & Dai; Elmore; Murnan & $3 / 3$ & + \\
\hline Self-control drinking water & & & Elmore & $1 / 1$ & + \\
\hline \multicolumn{6}{|l|}{ Behavior } \\
\hline Sleep duration & & Franckle & & $0 / 1$ & 0 \\
\hline Physical activity & & Jomaa & Senterre & $1 / 2$ & $?$ \\
\hline \multicolumn{6}{|l|}{ Consumption behavior } \\
\hline Consumption fruit/vegetables & & & Terry & $1 / 1$ & + \\
\hline Consumption milk & & Danyliw; Terry & Sichieri & $1 / 3$ & 0 \\
\hline $\begin{array}{l}\text { Consumption sugar-sweetened } \\
\text { beverages }\end{array}$ & Mantziki 2017; Terry & Danyliw; Sichieri & & $2 / 4$ & $? ?$ \\
\hline Consumption juice & & $\begin{array}{l}\text { Danyliw; Mantziki 2017; } \\
\text { Sichieri; Terry }\end{array}$ & & $0 / 4$ & 00 \\
\hline $\begin{array}{l}\text { Consumption moisture in } \\
\text { drinks }\end{array}$ & Kant & & & $1 / 1$ & - \\
\hline Consumption energy & & Kant & & $0 / 1$ & 0 \\
\hline Consumption amount & $\operatorname{Kant}(2-5 y)^{c}$ & & $\operatorname{Kant}(6-11 y)^{c}$ & $1 / 2$ & $?$ \\
\hline Consumption fat & & Kant & & $0 / 1$ & 0 \\
\hline Consumption protein & & Kant & & $0 / 1$ & 0 \\
\hline Consumption carbohydrate & & Kant & & $0 / 1$ & 0 \\
\hline Consumption sugars & Kant & & & $1 / 1$ & - \\
\hline Consumption fiber & & $\operatorname{Kant}(2-5 y)^{c}$ & $\operatorname{Kant}(6-11 y)^{c}$ & $1 / 2$ & $?$ \\
\hline Consumption sodium & & Kant & & $0 / 1$ & 0 \\
\hline Number of eating occasions & & Kant & Kakietek & $1 / 2$ & $?$ \\
\hline Consumption snack & & Kant $(2-5 y)^{c}$; Terry & $\operatorname{Kant}(6-11 y)^{c}$ & $1 / 3$ & 0 \\
\hline Having breakfast & & $\operatorname{Kant}(2-5 y)^{c}$ & $\operatorname{Kant}(6-11 y)^{c}$ & $1 / 2$ & $?$ \\
\hline
\end{tabular}


Table 2 Evidence of 63 included studies on the association between factors and water consumption among children (Continued)

\begin{tabular}{|c|c|c|c|c|c|}
\hline Factor & Negative association & No association & Positive association & $\mathrm{n} / \mathrm{N}^{\mathrm{a}}$ & Summary \\
\hline \multicolumn{6}{|l|}{ Interpersonal level } \\
\hline \multicolumn{6}{|l|}{ Parental socio-demographic } \\
\hline Education level (lower) & $\begin{array}{l}\text { Ebenegger; } \\
\text { Fernández-Alvira, 2013; Pinket } \\
\text { 2016b }\end{array}$ & Mantziki, 2015; Jomaa & & $3 / 5$ & - \\
\hline Income (lower) & Vieux, 2017 & $\begin{array}{l}\text { Beltrán-Aguilar; Drewnowski; } \\
\text { Jomaa; Vieux, } 2016\end{array}$ & & $1 / 6$ & 00 \\
\hline $\begin{array}{l}\text { Socioeconomic status } \\
\text { indicator }^{d} \text { (lower) }\end{array}$ & Cockburn; Terry & $\begin{array}{l}\text { Campos; Cunningham; } \\
\text { Jomaa; Makkes; Milla Tobarra; } \\
\text { Patel, } 2014\end{array}$ & Sohn & $2 / 9$ & 00 \\
\hline $\begin{array}{l}\text { Ethnic background/race } \\
\text { (non-white) }\end{array}$ & $\begin{array}{l}\text { Cockburn; Drewnowski; } \\
\text { Patel, } 2014\end{array}$ & $\begin{array}{l}\text { Beltrán-Aguilar; Dodd; } \\
\text { Ebenegger; Vieux, } 2017\end{array}$ & Sohn & $3 / 8$ & $? ?$ \\
\hline Generation immigration (first) & & & Parsons & $1 / 1$ & + \\
\hline Language (not English) & & Cockburn & Patel, 2014 & $1 / 2$ & $?$ \\
\hline Receives nutritional support & & Watowicz & & $0 / 1$ & 0 \\
\hline \multicolumn{6}{|l|}{ Parental psychosocial } \\
\hline Knowledge & & Pinket,2016a & & $0 / 1$ & 0 \\
\hline Self-efficacy & & & $\begin{array}{l}\text { Campbell; Mantziki, 2017; } \\
\text { Pinket,2016a }\end{array}$ & $3 / 3$ & + \\
\hline Perceives barriers & Cullen & Lora & & $1 / 2$ & $?$ \\
\hline Concern weight child & & Lora & & $0 / 1$ & 0 \\
\hline \multicolumn{6}{|l|}{ Parent-child interaction } \\
\hline Communicating health belief & & & Mantziki 2017 & $1 / 1$ & + \\
\hline Controlling feeding practice & & Inhulsen; Sleddens & & $0 / 2$ & 0 \\
\hline Emotional feeding practice & & $\begin{array}{l}\text { Inhulsen; Lora; Mantziki, 2017; } \\
\text { Sleddens; }\end{array}$ & Pinket,2016a & $1 / 5$ & 00 \\
\hline Restrictive feeding practice & & & $\begin{array}{l}\text { Mantziki 2017; Pinket,2016a; } \\
\text { Sleddens }\end{array}$ & $3 / 3$ & + \\
\hline Modelling feeding practice & & Mantziki 2017; Pinket,2016a & Sleddens & $1 / 3$ & 0 \\
\hline Negotiating feeding practice & & & Mantziki 2017 & $1 / 1$ & + \\
\hline Encouraging feeding practice & & Sleddens & Inhulsen; Pinket,2016a & $2 / 3$ & + \\
\hline Instrumental feeding practice & Inhulsen & Lora; Sleddens & & $1 / 3$ & 0 \\
\hline Pressure feeding practice & & Sleddens & & $0 / 1$ & 0 \\
\hline Monitoring feeding practice & & Mantziki 2017; Sleddens & & $0 / 2$ & 0 \\
\hline \multicolumn{6}{|l|}{ Environmental level } \\
\hline \multicolumn{6}{|l|}{ Home } \\
\hline Availability soft drinks & Mantziki 2017; Pinket,2016a & & & $2 / 2$ & - \\
\hline Availability fruit juice & Pinket,2016a & Mantziki 2017 & & $1 / 2$ & $?$ \\
\hline Availability water & & & Pinket,2016a & $1 / 1$ & + \\
\hline \multicolumn{6}{|l|}{ School } \\
\hline Free access water in classroom & & & Kaushik & $1 / 1$ & + \\
\hline Having school lunch & Condon & Dubuisson & Evans & $1 / 3$ & 0 \\
\hline School overall & & Vereecken & & $0 / 1$ & 0 \\
\hline $\begin{array}{l}\text { School compliant water } \\
\text { regulations }\end{array}$ & & Kakietek & & $0 / 1$ & 0 \\
\hline $\begin{array}{l}\text { School participates nutritious } \\
\text { meals }\end{array}$ & Kaketiek & & & $1 / 1$ & - \\
\hline
\end{tabular}


Table 2 Evidence of 63 included studies on the association between factors and water consumption among children (Continued)

\begin{tabular}{|c|c|c|c|c|c|}
\hline Factor & Negative association & No association & Positive association & $n / N^{a}$ & Summary ${ }^{b}$ \\
\hline $\begin{array}{l}\text { School participates nutrition } \\
\text { training }\end{array}$ & & Kakietek & & $0 / 1$ & 0 \\
\hline $\begin{array}{l}\text { School participates program } \\
\text { targeted low income families }\end{array}$ & & & Kaketiek & $1 / 1$ & + \\
\hline School operating hours & & & Kakietek & $1 / 1$ & + \\
\hline Classroom size & & Kakietek & & $0 / 1$ & 0 \\
\hline Student-teacher ratio & & Kakietek & & $0 / 1$ & 0 \\
\hline Teaching staff turnover & & & Kakietek & $1 / 1$ & + \\
\hline \multicolumn{6}{|l|}{ Consumption place/time } \\
\hline Eating at other's house & & Ayala & & $0 / 1$ & 0 \\
\hline Eating at restaurant & Ayala & & & $1 / 1$ & - \\
\hline Type of restaurant & & Ayala & & $0 / 1$ & 0 \\
\hline Meal time (lunch) & & & Campos & $1 / 1$ & + \\
\hline Consumption during meal & & & Fenandez-Alvira, 2014 & $1 / 1$ & + \\
\hline Consumption on weekday & & & Hoffmann & $1 / 1$ & + \\
\hline \multicolumn{6}{|l|}{ Other } \\
\hline Country & & & De Craemer; Guelinckx & $2 / 2$ & + \\
\hline Region & & Cockburn & Vieux, 2017 & $1 / 2$ & $?$ \\
\hline Outside temperature & & Sohn; Terry & Beltrán-Aguilar & $1 / 3$ & 0 \\
\hline Season (summer) & & Vieux, 2017 & Barraj & $1 / 2$ & $?$ \\
\hline Time & & & $\begin{array}{l}\text { Bleich; Haroun; Sichert- } \\
\text { Hellert; Zohouri }\end{array}$ & $4 / 4$ & ++ \\
\hline
\end{tabular}

Longitudinal and repeated cross-sectional studies are shown in bold. a) $\mathrm{n}=$ number studies reporting significant association; $\mathrm{N}=$ total number studies investigating association. b) For 3 studies: (0) no association, 0-33\% of studies showed a significant association; (?) inconsistent association, 34-59\% of studies reported significant associations; (+) positive or (-) negative association, $60-100 \%$ of studies demonstrated significant associations. For 4 or more studies a summary of these associations is presented with (00), (??), (++), or (--) respectively. c) These studies stratified associations between factor and water consumption by age group, when associations were different, results are presented by age group and counted as 2 studies. d) Public/private school ( 2 studies), socio-economic index for areas, food insecurity, eligibility free/reduced lunch, health care card recipients, poverty-income ratio, employment status, index based on education and occupation

girls consuming less water (8/19 studies; 18 (repeated) cross-sectional 1 longitudinal). There was inconsistent evidence for a negative association between consumption of SSBs and water consumption (2/4 studies; all cross-sectional) and no evidence of an association between milk consumption ( $1 / 3$ studies; all cross-sectional) or juice consumption (0/4 studies; all cross-sectional) and water consumption.

\section{Interpersonal factors}

Twenty-one interpersonal level factors were identified, of which 11 factors were only studied in one or two studies. In total, 11 factors were studied in a longitudinal study. There was evidence for a positive association between parent's education level and the child's water consumption (3/5 studies; all cross-sectional). In contrast, there was no evidence of an association between family income (1/6 studies; all cross-sectional) or other indicators of socioeconomic status (2/9 studies; 8 cross-sectional 1 longitudinal) and child's water consumption. There was evidence for a positive association between self-efficacy of the parents regarding healthy nutrition and child's water consumption (3/3 studies; all cross-sectional). Among the parental feeding practices, there was evidence for positive associations between restriction (3/3 studies; 2 cross-sectional 1 longitudinal) and encouraging healthy eating/drinking ( $2 / 3$ studies; 2 cross-sectional 1 longitudinal) and the child's water consumption. There was inconsistent evidence that children of parents with a nonwhite background consume less water ( $3 / 8$ studies; 7 crosssectional 1 longitudinal). There was no evidence for emotional feeding practices (1/5 studies; 4 cross-sectional 1 longitudinal), modelling ( $1 / 3$ studies; 2 cross-sectional 1 longitudinal), instrumental feeding practices ( $1 / 3$ studies; 2 cross-sectional 1 longitudinal).

\section{Environmental factors}

Twenty-five environmental level factors were identified, of which 22 factors were only studied in one or two studies. Two factors were studied in a longitudinal study. There was evidence for an increasing trend in children's water consumption in more recent study years compared to 
earlier study years (4/4 studies; 3 repeated cross-sectional 1 longitudinal). There was some evidence for country differences in water consumption among children $(2 / 2$ studies; both cross-sectional). There was some evidence for a negative association between home availability of soft drinks and water consumption ( $2 / 2$ studies; both crosssectional). Two cross-sectional studies found positive associations between the availability of water and water consumption: one focusing on availability in the home, and the other on free access to water in the classroom. Evidence for most factors relating to school nutrition policies was inconsistent and studied by single studies. There was no evidence for an association between having school lunch and water consumption (1/3 studies; all crosssectional).

\section{Discussion}

This review aimed to summarize the evidence of factors associated with water consumption among children aged 2-12 years. A large number of factors at the individual, interpersonal and environmental levels were identified and there was evidence that several factors were associated with water consumption in children. However, the majority of factors were only investigated by one or two studies and most studies were cross-sectional. Research on childhood water consumption appears to be a relatively new field as more than three-quarters of the studies identified were published in 2010 or later. Many older studies on beverage consumption did not measure water consumption [105]. However, several interventions have aimed to replace children's consumption of SSBs by water $[20,21,106]$. This highlights the importance of studying the factors associated with water consumption in children, alongside the factors associated with SSB consumption, as the drivers, motivators, and barriers may differ between beverage categories.

\section{Individual factors}

There was consistent evidence for a positive association between both the child's self-efficacy to drink enough water and water consumption. Self-efficacy has also been associated with other healthy dietary behaviors and prevention of weight gain $[41,107]$. Although, to our knowledge, there have not been any interventions targeting self-efficacy in order to promote water intake, this could be a promising approach. In the domain of nutrition, a Canadian intervention that included peer-based healthy living lessons among primary-school children found a significant increase in self-efficacy, and also an improvement in dietary intake [108].

The evidence for an association between the child's age and sex and water consumption was inconsistent. This could partly be due to differences in measurement of water intake. The seven studies that found a positive association between age and water consumption generally measured water consumption in volume per day, whereas the two studies that found a negative association between the child's age and water consumption measured water consumption in volume per kilogram of bodyweight per day. In addition, around half of all studies included in the review measured children's water consumption in number of servings per day or as a bivariate outcome (consumed water or not). As water intake recommendations are expressed in liters or milliliters per day [109, 110], it would be valuable for future studies to use these measures in order to increase comparability between studies, and to dietary guidelines.

The evidence for a negative association between SSB consumption and water consumption was mixed and there was no evidence of associations between consumption of milk or juice and water consumption in children. More research needs to be done on the interrelation between the consumption of different types of beverage categories such as SSBs (e.g. soft drinks, fruit drinks and energy drinks), juice and milk among children. It is unclear if and when water consumption replaces the consumption of other beverages or whether water is consumed in addition to other beverages in non-experimental settings.

We found mixed evidence for a positive association between BMI and water consumption. Children with a higher BMI may consume both more water as well as SSBs compared with children with a lower BMI, which is found in some studies [31, 111]. However, other studies have found non-significant differences in overall beverage consumption patterns according to weight status [60,81]. Interestingly, diet drink consumption has sometimes also been found to be higher among overweight persons $[81,112]$. It may be possible that overweight children compensate calorie intake from solid foods by drinking water.

\section{Interpersonal factors}

Restrictive parenting practices towards unhealthy nutrition and encouraging parenting practices towards healthy nutrition were associated with higher water consumption in children. Of the three studies that measured the association between parental modelling and the child's water consumption, only the one longitudinal study found an association. The broader literature generally identifies parent's restrictive-, encouraging-, and modelling practices as beneficial to children's diet quality, although findings are mixed [35, 41, 113]. However, different feeding practices may be required to promote intake of healthy foods and drinks than those that decrease intake of unhealthy foods, thus findings related to water intake may more closely reflect those related to healthy food intake (e.g., fruits and vegetables), rather 
than those related to unhealthy beverages (e.g., SSBs). Further, different feeding practices may be appropriate for younger versus older children, thus potentially contributing to some mixed findings in the literature [113]. Promoting specific parental feeding practices appears to be a promising strategy for the promotion of water consumption among children, although more studies need to be done to determine the specific feeding practices that are the most beneficial.

Similar to our findings for children's self-efficacy, there was also consistent evidence for a positive association between the parent's self-efficacy towards healthy nutrition and the child's water consumption. A Dutch parenting intervention among parents of overweight and obese children found that parent's self-efficacy was modifiable, and found positive effects on children's soft drink consumption [114]. It remains to be explored how parent's self-efficacy can be addressed with respect to encouraging children to consume water more often.

With regard to demographic factors, we found evidence for an association between parental education level and child's water consumption, but no evidence for family income or other indicators of socioeconomic status. The findings related to ethnic background were inconclusive. Other reviews also found mixed evidence regarding the association between socioeconomic status or ethnic background and healthy food and energy-balance behaviors $[35,115]$.

\section{Environmental factors}

Environmental factors relating to water consumption in children appear to be largely understudied. The most consistent evidence was found for an increasing trend in children's water consumption over time. The most recent of these studies was done in the US and found an increase in children's water consumption from 2004 to 2014; as well as a decreasing trend in children's SSB consumption [77]. Among public health efforts that could have impacted on this trend, the authors mention beverage taxes that were implemented in several states across the US [77].

Some studies included in our review found that availability and access to water at home or at school was associated with higher water consumption- and availability of SSBs with lower water consumption. Availability and accessibility have also been consistently associated with fruit and vegetable consumption in children [40-42]. Giving children free access to water during school hours could be a key strategy to promote children's water consumption. The association between school nutrition policies and water consumption in children was only studied by single studies. The relationship between school nutrition policies and children's water consumption could be a promising field for further study.

\section{Strengths and limitations}

To our knowledge, this was the first systematic review to investigate factors associated with water consumption in children. Previous reviews have focused on factors associated with SSB consumption in children and intervention studies aiming to reduce SSB intake $[35,116]$. We performed an extended literature search in seven databases and followed a rigorous procedure for the selection of studies [117]. In addition, the references of included studies were hand-searched, which resulted in the inclusion of two additional studies. Some limitations of our review must also be acknowledged. Because we only included published studies, there is a possibility of publication bias in the findings of this review [118]. Furthermore, we only studied articles published in English and thus might have missed studies that were published in other languages. Also, there were not enough studies done on each factor to be able to stratify our results by age group. However, factors associated with water consumption might vary according to children's age. Most studies included in this review had a cross-sectional study design, therefore reverse causation cannot be excluded. For example, while a parental feeding practice could impact the child's eating and drinking behavior, the child's eating habits could also influence the feeding practices parents adopt $[119,120]$. We found indications for potential bias in most of the studies. This was largely due to potential bias in the applied measurements of water consumption, where many studies relied on retrospective self-reported dietary data. Furthermore, studies among younger children relied on parental report of children's consumption of water. These methods have been found to be imprecise due to underreporting of food and beverage intake because of poor recall of the actual amounts consumed [121, 122]. Quantities of water, in particular, may be underreported as it is often consumed outside of regular mealtimes and over the course of the day. These measures may also be biased due to children and their parents giving socially desirable answers $[121,123]$; that is to say, (parents of) children with a low water consumption could be tempted to over report the water consumption.

\section{Conclusions}

A large number of factors at the individual, interpersonal and environmental level were identified that were associated with water consumption, however many of these factors were studied by only one or two studies. There is some evidence for an association between potentially modifiable factors (parental and child self-efficacy and specific parental feeding practices) and water consumption, however most of this evidence comes from crosssectional studies. More research is necessary to investigate environmental, parental and child-related factors that are currently under-studied and could further inform intervention strategies. 


\section{Additional files}

Additional file 1: Search strategy of the review on factors associated with water consumption among children. (DOCX $18 \mathrm{~kb}$ )

Additional file 2: ROBINS-I risk of bias protocol specified for the review on factors associated with water consumption among children. (DOCX $25 \mathrm{~kb}$ )

Additional file 3: Characteristics, associations and risk of bias of studies included in the review on factors associated with water consumption among children. (DOCX $85 \mathrm{~kb}$ )

\section{Abbreviations}

BMI: Body mass index; PRISMA: Preferred reporting items of systematic reviews and meta-analyses; ROBINS-I: Risk Of Bias In Nonrandomized Studies of Interventions; SSB: Sugar sweetened beverage

\section{Acknowledgements}

The authors thank Wichor Bramer from the Erasmus MC Medical Library for developing the search strategies for the bibliographic databases.

\section{Authors' contributions}

The study was developed by HR and FC. HR and CF designed the methodology for the review. CF and LW drafted the search strategy together with information specialists at the medical library of the Erasmus Medical Centre, did screening of records, extraction of data and assessment of bias of studies. CF drafted the manuscript and LW, HR, FC and LF revised the manuscript for important intellectual content. All authors approved the final manuscript.

\section{Funding}

This study was funded by Nestlé Waters. Nestlé Waters had no role in the study design, collection of data, analysis of data and interpretation of results.

\section{Availability of data and materials}

Not applicable.

\section{Ethics approval and consent to participate}

Not applicable.

\section{Consent for publication}

Not applicable.

\section{Competing interests}

CF, LW and HR have no competing interests. FC is employed by Nestlé Waters and LRF is employed by Nestlé Research.

\section{Author details}

'Department of Public Health, Erasmus University Medical Center, Wytemaweg 80, 3015, CN, Rotterdam, The Netherlands. 'Nestlé Waters MT, Issy-les-Moulineaux, France. ${ }^{3}$ Nestlé Research, Vers-chez-les-Blanc, Lausanne, Switzerland.

Received: 27 December 2018 Accepted: 29 July 2019

Published online: 13 August 2019

\section{References}

1. de Onis M, Blossner M, Borghi E. Global prevalence and trends of overweight and obesity among preschool children. Am J Clin Nutr. 2010;92(5):1257-64.

2. Ogden CL, Carroll MD, Lawman HG, Fryar CD, Kruszon-Moran D, Kit BK, et al. Trends in obesity prevalence among children and adolescents in the United States, 1988-1994 through 2013-2014. JAMA. 2016;315(21):2292-9.

3. Dehghan M, Akhtar-Danesh N, Merchant AT. Childhood obesity, prevalence and prevention. Nutr J. 2005;4:24.

4. Mokdad AH, Ford ES, Bowman BA, Dietz WH, Vinicor F, Bales VS, et al. Prevalence of obesity, diabetes, and obesity-related health risk factors, 2001. JAMA. 2003;289(1):76-9.

5. UNICEF-WHO-World Bank. Levels and trends in child malnutrition: UNICEF-WHO-World Bank joint child malnutrition estimates. UNICEF, New York; WHO, Geneva; World Bank, Washington DC: ; 2018.
6. Skinner AC, Ravanbakht SN, Skelton JA, Perrin EM, Armstrong SC. Prevalence of Obesity and Severe Obesity in US Children. Pediatrics. 1999-2016:2018.

7. Wijnhoven TM, van Raaij JM, Spinelli A, Starc G, Hassapidou M, Spiroski I, et al. WHO European childhood obesity surveillance initiative: body mass index and level of overweight among 6-9-year-old children from school year 2007/2008 to school year 2009/2010. BMC Public Health. 2014;14:806.

8. Whitaker RC, Wright JA, Pepe MS, Seidel KD, Dietz WH. Predicting obesity in young adulthood from childhood and parental obesity. N Engl J Med. 1997:337(13):869-73.

9. Aarestrup J, Bjerregaard LG, Gamborg M, Angquist L, Tjonneland A, Overvad K, et al. Tracking of body mass index from 7 to 69 years of age. Int J Obes. 2016;40(9):1376-83.

10. World Health Organization. Taking action on childhood obesity report. Geneva, Switzerland: World Health Organization; 2018.

11. Union E. EU action plan on childhood obesity 2014-2020 Brussels. European Commission: Belgium; 2014.

12. Huang TT, Drewnosksi A, Kumanyika S, Glass TA. A systems-oriented multilevel framework for addressing obesity in the 21 st century. Prev Chronic Dis. 2009;6(3):A82

13. Azais-Braesco V, Sluik D, Maillot M, Kok F, Moreno LA. A review of total \& added sugar intakes and dietary sources in Europe. Nutr J. 2017;16(1):6.

14. Wang YC, Bleich SN, Gortmaker SL. Increasing caloric contribution from sugar-sweetened beverages and 100\% fruit juices among US children and adolescents, 1988-2004. Pediatrics. 2008;121(6):e1604-14.

15. Malik VS, Schulze MB, Hu FB. Intake of sugar-sweetened beverages and weight gain: a systematic review. Am J Clin Nutr. 2006;84(2):274-88.

16. Malik VS, Willett WC, Hu FB. Sugar-sweetened beverages and BMI in children and adolescents: reanalyses of a meta-analysis. Am J Clin Nutr. 2009;89(1):438-9 author reply 9-40.

17. Hu FB. Resolved: there is sufficient scientific evidence that decreasing sugar-sweetened beverage consumption will reduce the prevalence of obesity and obesity-related diseases. Obes Rev. 2013;14(8):606-19.

18. Zheng M, Rangan A, Olsen NJ, Andersen LB, Wedderkopp N, Kristensen P, et al. Substituting sugar-sweetened beverages with water or milk is inversely associated with body fatness development from childhood to adolescence. Nutrition. 2015:31(1):38-44.

19. Zheng M, Allman-Farinelli M, Heitmann BL, Rangan A. Substitution of sugar-sweetened beverages with other beverage alternatives: a review of long-term health outcomes. J Acad Nutr Diet. 2015;115(5):767-79.

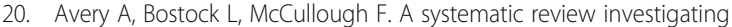
interventions that can help reduce consumption of sugar-sweetened beverages in children leading to changes in body fatness. J Hum Nutr Diet. 2015;28(Suppl 1):52-64.

21. Beets MW, Weaver RG, Turner-McGrievy G, Huberty J, Moore JB, Ward DS, et al. Two-year healthy eating outcomes: An RCT in afterschool programs. Am J Prev Med. 2017;53(3):316-26.

22. Waters E, Gibbs L, Tadic M, Ukoumunne OC, Magarey A, Okely AD, et al. Cluster randomised trial of a school-community child health promotion and obesity prevention intervention: findings from the evaluation of fun ' $\mathrm{n}$ healthy in Moreland! BMC Public Health. 2017;18(1):92.

23. Klesges RC, Obarzanek E, Kumanyika S, Murray DM, Klesges LM, Relyea GE, et al. The Memphis Girls' health enrichment multi-site studies (GEMS): An evaluation of the efficacy of a 2-year obesity prevention program in African American girls. Arch Pediatr Adolesc Med. 2010;164(11):1007-14.

24. Muckelbauer R, Libuda L, Clausen K, Toschke AM, Reinehr T, Kersting M. Promotion and provision of drinking water in schools for overweight prevention: randomized, controlled cluster trial. Pediatrics. 2009;123(4):e661-e7.

25. Park S, Lin M, Onufrak S, Li R. Association of sugar-sweetened beverage intake during infancy with dental caries in 6-year-olds. Clin Nutr Res. 2015;4(1):9-17.

26. Bernabe E, Vehkalahti MM, Sheiham A, Aromaa A, Suominen AL. Sugar-sweetened beverages and dental caries in adults: a 4-year prospective study. J Dent 2014;42(8):952-8

27. Popkin BM, Armstrong LE, Bray GM, Caballero B, Frei B, Willett WC. A new proposed guidance system for beverage consumption in the United States. Am J Clin Nutr. 2006:83(3):529-42.

28. American Academy of Pediatrics - Committee on Nutrition the Council on Sports Medicine Fitness. Sports drinks and energy drinks for children and adolescents: are they appropriate? Pediatrics. 2011;127(6):1182-9.

29. Nutrition ECo, Agostoni C, Braegger C, Decsi T, Kolacek S, Koletzko B, et al. Role of dietary factors and food habits in the development of childhood 
obesity: a commentary by the ESPGHAN committee on Nutrition. J Pediatr Gastroenterol Nutr. 2011;52(6):662-9.

30. Guelinckx I, Iglesia I, Bottin JH, De Miguel-Etayo P, Gonzalez-Gil EM, Salas-Salvado J, et al. Intake of water and beverages of children and adolescents in 13 countries. Eur J Nutr. 2015;54(Suppl 2):69-79.

31. Vieux F, Maillot M, Constant F, Drewnowski A. Water and beverage consumption patterns among 4 to 13-year-old children in the United Kingdom. BMC Public Health. 2017;17(1):479.

32. Drewnowski A, Rehm CD. Water and beverage consumption among children age 4-13y in the United States: analyses of 2005-2010 NHANES data: nutritionj.biomedcentral.com; 2013.

33. Piernas C, Barquera S, Popkin BM. Current patterns of water and beverage consumption among Mexican children and adolescents aged 1-18 years: analysis of the Mexican National Health and Nutrition survey 2012. Public Health Nutr. 2014;17(10):2166-75.

34. Vieux F, Maillot M, Constant F, Drewnowski A. Water and beverage consumption among children aged 4-13 years in France: analyses of INCA 2 (Étude Individuelle Nationale des Consommations Alimentaires 2006-2007) data. Public Health Nutr. 2016;19(13):2305-14.

35. Mazarello Paes V, Hesketh K, O'Malley C, Moore H, Summerbell C, Griffin S, et al. Determinants of sugar-sweetened beverage consumption in young children: a systematic review. Obes Rev. 2015;16(11):903-13.

36. Bronfenbrenner U. Toward an experimental ecology of human-development. Am Psychol. 1977;32(7):513-31.

37. Bandura A. Self-efficacy : the exercise of control. New York: W.H. Freeman; 2003.

38. Shloim N, Edelson LR, Martin N, Hetherington MM. Parenting styles, feeding styles, feeding practices and weight status in 4-12 year-old children: a systematic review of the literature. Front Psychol. 2015;6.

39. Blissett J. Relationships between parenting style, feeding style and feeding practices and fruit and vegetable consumption in early childhood. Appetite. 2011;57(3):826-31.

40. Blanchette $L$, Brug J. Determinants of fruit and vegetable consumption among 6-12-year-old children and effective interventions to increase consumption. J Hum Nutr Diet. 2005;18(6):431-43.

41. Rasmussen M, Krolner R, Klepp Kl, Lytle L, Brug J, Bere E, et al. Determinants of fruit and vegetable consumption among children and adolescents: a review of the literature. Part I: Quantitative studies Int J Behav Nutr Phys Act. 2006;3:22

42. Ong JX, Ullah S, Magarey A, Miller J, Leslie E. Relationship between the home environment and fruit and vegetable consumption in children aged 6-12 years: a systematic review. Public Health Nutr. 2017;20(3):464-80.

43. Sterne JA, Hernan MA, Reeves BC, Savovic J, Berkman ND, Viswanathan M, et al. ROBINS-l: a tool for assessing risk of bias in non-randomised studies of interventions. BMJ. 2016:355:14919.

44. The ROBINS-E tool (Risk of Bias Instrument for Non-randomized Studies of Exposures) [Available from: https://www.bristol.ac.uk/population-healthsciences/centres/cresyda/barr/riskofbias/robins-e/.

45. Sallis JF, Prochaska JJ, Taylor WC. A review of correlates of physical activity of children and adolescents. Med Sci Sports Exerc. 2000;32(5):963-75.

46. Moher D, Liberati A, Tetzlaff J, Altman DG, Group P. Preferred reporting items for systematic reviews and meta-analyses: the PRISMA statement. Ann Intern Med. 2009;151(4):264-9 W64.

47. Bougatsas D, Arnaoutis G, Panagiotakos DB, Seal AD, Johnson EC, Bottin JH, et al. Fluid consumption pattern and hydration among 8-14 years-old children. Eur J Clin Nutr. 2018;72(3):420-7.

48. Cardon G, De Bourdeaudhuij I, lotova V, Latomme J, Socha P, Koletzko $B$, et al. Health related behaviours in normal weight and overweight preschoolers of a large pan-european sample: The toybox-study. PLoS ONE. 2016;11(3).

49. Coppinger $T$, Jeanes $Y$, Mitchell $M$, Reeves $S$. Beverage consumption and BMl of British schoolchildren aged 9-13 years. Public Health Nutr. 2013;16(7):1244-9.

50. De Craemer M, Lateva M, lotova V, De Decker E, Verloigne M, De Bourdeaudhuij I, et al. Differences in energy balance-related behaviours in European preschool children: The ToyBox-study. PLoS ONE. 2015;10(3).

51. Dubuisson C, Lioret S, Dufour A, Calamassi-Tran G, Volatier JL, Lafay L, et al. The relationship between school lunch attendance and the food intakes of French schoolchildren aged 3-17 years. Public Health Nutr. 2015;18(9):1647-57.

52. Ebenegger V, Marques-Vidal PM, Nydegger A, Laimbacher J, Niederer I, Bürgi $F$, et al. Independent contribution of parental migrant status and educational level to adiposity and eating habits in preschool children. Eur J Clin Nutr. 2011;65(2):210-8.

53. Evans CE, Mandl V, Christian MS, Cade JE. Impact of school lunch type on nutritional quality of English children's diets. Public Health Nutr. 2016;19(1):36-45.

54. Fenández-Alvira JM, Iglesia I, Ferreira-Pêgo C, Babio N, Salas-Salvadó J, Moreno LA. Fluid intake in Spanish children and adolescents; a cross-sectional study. Nutr Hosp. 2014;29(5):1163-70.

55. Fernández-Alvira JM, Mouratidou T, Bammann K, Hebestreit A, Barba G, Sieri S, et al. Parental education and frequency of food consumption in European children: the IDEFICS study. Public Health Nutr. 2013;16(3):487-98.

56. Haroun D, Harper C, Wood L, Nelson M. The impact of the food-based and nutrient-based standards on lunchtime food and drink provision and consumption in primary schools in England. Public Health Nutr. 2011:14(2):209-18

57. Inhulsen MM, Merelle SY, Renders CM. Parental feeding styles, young children's fruit, vegetable, water and sugar-sweetened beverage consumption, and the moderating role of maternal education and ethnic background. Public Health Nutr. 2017;20(12):2124-33.

58. Kaushik A, Mullee MA, Bryant TN, Hill CM. A study of the association between children's access to drinking water in primary schools and their fluid intake: can water be 'cool' in school? Child Care Health Dev. 2007;33(4):409-15.

59. Lioret S, Dubuisson C, Dufour A, Touvier M, Calamassi-Tran G, Maire B, et al. Trends in food intake in French children from 1999 to 2007: results from the INCA (etude Individuelle Nationale des Consommations Alimentaires) dietary surveys. Br J Nutr. 2010;103(4):585-601.

60. Maffeis C, Tommasi M, Tomasselli F, Spinelli J, Fornari E, Scattolo N, et al. Fluid intake and hydration status in obese vs normal weight children. Eur J Clin Nutr. 2016;70(5):560-5.

61. Mantziki K, Renders CM, Seidell JC. Water consumption in European children: Associations with intake of fruit juices, soft drinks and related parenting practices. Int J Environ Res Public Health. 2017;14(6).

62. Mantziki K, Vassilopoulos A, Radulian G, Borys JM, Du Plessis H, Gregório MJ, et al. Inequities in energy-balance related behaviours and family environmental determinants in European children: baseline results of the prospective EPHE evaluation study. BMC Public Health. 2015;15:1203.

63. Milla Tobarra M, Garcia Hermoso A, Lahoz Garcia N, Notario Pacheco B, Lucas de la Cruz L, Pozuelo Carrascosa DP, et al. The relationship between socioeconomic status and beverage consumption in children: the Cuenca study. Nutr Hosp 2018;0(0):368-374.

64. Papandreou D, Andreou E, Heraclides A, Rousso I. Is beverage intake related to overweight and obesity in school children? Hippokratia. 2013;17(1):42-6.

65. Parsons S, Godson JH, Williams SA, Cade JE. Are there intergenerational differences in the diets of young children born to first- and secondgeneration Pakistani Muslims in Bradford, West Yorkshire, UK? J Hum Nutr Diet. 1999;12(2):113-22.

66. Petter LPM, OBH J, Rolles CJ. Is water out of vogue? A survey of the drinking habits of 2-7 years olds. Arch Dis Child. 1995;72(2):137-40.

67. Pinket AS, De Craemer M, De Bourdeaudhuij I, Deforche B, Cardon G, Androutsos $\mathrm{O}$, et al. Can parenting practices explain the differences in beverage intake according to socio-economic status: The toybox-study. Nutrients. 2016;8(10).

68. Pinket AS, De Craemer M, Maes L, De Bourdeaudhuij I, Cardon G, Androutsos O, et al. Water intake and beverage consumption of pre-schoolers from six European countries and associations with socio-economic status: the ToyBox-study. Public Health Nutr. 2016;19(13):2315-25.

69. Senterre C, Dramaix M, Thiébaut I. Fluid intake survey among schoolchildren in Belgium. BMC Public Health. 2014;14:651.

70. Sichert-Hellert W, Kersting M, Manz F. Fifteen year trends in water intake in German children and adolescents: results of the DONALD study. Acta Paediatr Int J Paediatr. 2001;90(7):732-7.

71. Sleddens EFC, Kremers SPJ, Stafleu A, Dagnelie PC, De Vries NK, Thijs C. Food parenting practices and child dietary behavior. Prospective relations and the moderating role of general parenting. Appetite. 2014;79:42-50.

72. Vereecken C, Huybrechts I, Maes L, De Henauw S. Food consumption among preschoolers. Does the school make a difference? Appetite. 2008:51(3):723-6.

73. Zohouri FV, Rugg-Gunn AJ, Fletcher ES, Hackett AF, Moynihan PJ, Mathers JC, et al. Changes in water intake of Northumbrian adolescents 1980 to 2000. Br Dent J. 2004;196(9):547-52 discussion 37. 
74. Ayala GX, Rogers M, Arredondo EM, Campbell NR, Baquero B, Duerksen SC, et al. Away-from-home food intake and risk for obesity: examining the influence of context. Obesity. 2008;16(5):1002-8.

75. Barraj L, Scrafford C, Lantz J, Daniels C, Mihlan G. Within-day drinking water consumption patterns: results from a drinking water consumption survey. J Expos Sci Environ Epidemiol. 2009;19(4):382-95.

76. Beltrán-Aguilar ED, Barker L, Sohn W, Wei L. Water intake by outdoor temperature among children aged 1-10 years: implications for community water fluoridation in the U.S. Public Health Rep. 2015;130(4):362-71.

77. Bleich SN, Vercammen KA, Koma JW, Li ZH. Trends in beverage consumption among children and adults, 2003-2014. Obesity. 2018;26(2):432-41.

78. Condon EM, Crepinsek MK, Fox MK. School meals: types of foods offered to and consumed by children at lunch and breakfast. J Am Diet Assoc. 2009;109(2 Suppl):S67-78.

79. Cullen KW, Baranowski T, Klesges LM, Watson K, Sherwood NE, Story M, et al. Anthropometric, parental, and psychosocial correlates of dietary intake of African-American girls. Obes Res. 2004;12(Suppl):20S-31S.

80. Cunningham TJ, Barradas DT, Rosenberg KD, May AL, Kroelinger CD, Ahluwalia IB. Is maternal food security a predictor of food and drink intake among toddlers in Oregon? Matern Child Health J. 2012;16(Suppl 2):339-46.

81. Dodd AH, Briefel R, Cabili C, Wilson A, Crepinsek MK. Disparities in consumption of sugar-sweetened and other beverages by race/ethnicity and obesity status among United States schoolchildren. J Nutr Educ Behav. 2013:45(3):240-9.

82. Danyliw AD, Vatanparast H, Nikpartow N, Whiting SJ. Beverage intake patterns of Canadian children and adolescents. Public Health Nutr. 2011;14(11):1961-9.

83. Elmore S, Sharma M. Predicting childhood obesity prevention behaviors using social cognitive theory among upper elementary african-american children. Int Q Community Health Educ. 2013:34(2):187-97.

84. Franckle RL, Falbe J, Gortmaker S, Ganter C, Taveras EM, Land T, et al. Insufficient sleep among elementary and middle school students is linked with elevated soda consumption and other unhealthy dietary behaviors. Prev Med. 2015;74:36-41

85. Hoffmann DA, Marx JM, Burmeister JM, Musher-Eizenman DR. Friday night is pizza night: A comparison of children's dietary intake and maternal perceptions and feeding goals on weekdays and weekends. Int J Environ Res Public Health. 2018;15(4).

86. Kakietek J, Osuji TA, O'Dell SA, Breck A, Kettel KL. Compliance with new York City's beverage regulations and beverage consumption among children in early child care centers. Prev Chronic Dis. 2014;11:E180.

87. Kant AK, Graubard BI. Contributors of water intake in US children and adolescents: associations with dietary and meal characteristics - National Health and Nutrition examination survey 2005-2006. Am J Clin Nutr. 2010;92(4):887-96

88. Lora KR, Hubbs-Tait L, Ferris AM, Wakefield D. African-American and Hispanic children's beverage intake: differences in associations with desire to drink, fathers' feeding practices, and weight concerns. Appetite. 2016;107:558-67.

89. Patel Al, Bogart LM, Klein DJ, Cowgill B, Uyeda KE, Hawes-Dawson J, et al. Middle school student attitudes about school drinking fountains and water intake. Acad Pediatr. 2014;14(5):471-7.

90. Patel Al, Shapiro DJ, Wang YC, Cabana MD. Sociodemographic characteristics and beverage intake of children who drink tap water. Am J Prev Med. 2013:45(1):75-82

91. Sharma M, Wagner DI, Wilkerson J. Predicting childhood obesity prevention behaviors using social cognitive theory. Int Q Community Health Educ. 2005;24(3):191-203.

92. Sohn W, Heller KE, Burt BA. Fluid consumption related to climate among children in the United States. J Public Health Dent. 2001;61(2):99-106.

93. Wang D, van der Horst K, Jacquier E, Eldridge AL. Snacking among US children: patterns differ by time of day. J Nutr Educ Behav. 2016;48(6):369-75.

94. Watowicz RP, Taylor CA. A comparison of beverage intakes in US children based on WIC participation and eligibility. J Nutr Educ Behav. 2014:46(3):S59-64

95. Campos R, Montenegro-Bethancourt G, Vossenaar M, Doak CM, Solomons NW. Volume, frequency and participation in plain drinking water consumption by third and fourth-grade schoolchildren in Quetzaltenango. Guatemala Asia Pac J Clin Nutr. 2009;18(2):164-70.

96. Makkes S, Montenegro-Bethancourt G, Groeneveld IF, Doak CM, Solomons NW. Beverage consumption and anthropometric outcomes among schoolchildren in Guatemala. Matern Child Nutr. 2011;7(4):410-20.
97. Sichieri R, Yokoo EM, Pereira RA, Veiga GV. Water and sugar-sweetened beverage consumption and changes in BMI among Brazilian fourth graders after 1-year follow-up. Public Health Nutr. 2013;16(1):73-7.

98. Feferbaum R, de Abreu LC, Leone C. Fluid intake patterns: an epidemiological study among children and adolescents in Brazil. BMC Public Health. 2012;12:1005.

99. Campbell K, Hesketh K, Silverii A, Abbott G. Maternal self-efficacy regarding children's eating and sedentary behaviours in the early years: associations with children's food intake and sedentary behaviours. Int J Pediatr Obes. 2010;5(6):501-8.

100. Cockburn N, Lalloo R, Schubert L, Ford PJ. Beverage consumption in Australian children. Eur J Clin Nutr. 2017:1-9.

101. Terry D, Ervin K, Soutter E, Spiller R, Nogare ND, Hamilton AJ. Do not "let them eat cake": Correlation of food-consumption patterns among rural primary school children from welfare and non-welfare households. Int J Environ Res Public Health. 2017;14(1)

102. Dai CL, Sharma M. Predicting childhood obesity prevention behaviors using social cognitive theory for elementary school students in Taiwan. Int J Health Promot Edu. 2014:52(6):339-45.

103. Jomaa L, Hwalla N, Constant F, Naja F, Nasreddine L. Water and beverage consumption among children aged 4-13 years in Lebanon: Findings from a national cross-sectional study. Nutrients. 2016;8(9).

104. Murnan J, Sharma M, Lin D. Predicting childhood obesity prevention behaviors using social cognitive theory: children in China. Int Q Community Health Educ. 2006;26(1):73-84.

105. Ozen AE, Bibiloni Mdel M, Pons A, Tur JA. Fluid intake from beverages across age groups: a systematic review. J Hum Nutr Diet. 2015:28(5):417-42.

106. Beech BM, Klesges RC, Kumanyika SK, Murray DM, Klesges L, McClanahan B, et al. Child- and parent-targeted interventions: The Memphis GEMS pilot study. Ethni Dis. 2003;13(1 SUPPL. 1):S1-40-S1-53.

107. Ball K, Crawford D. An investigation of psychological, social and environmental correlates of obesity and weight gain in young women. Int J Obes. 2006:30(8):1240-9.

108. Santos RG, Durksen A, Rabbanni R, Chanoine JP, Lamboo Miln A, Mayer T, et al. Effectiveness of peer-based healthy living lesson plans on anthropometric measures and physical activity in elementary school students: a cluster randomized trial. JAMA Pediatr. 2014;168(4):330-7.

109. European Food Safety Authority. Scientific Opinion on Dietary Reference Values for water. EFS2 EFSA Journal. 2010;8(3).

110. Institute of Medicine (US). Dietary reference intakes for water, potassium, sodium, chloride, and sulfate. Washington, DC: National Academies Press; 2005

111. Watowicz RP, Anderson SE, Kaye GL, Taylor CA. Energy contribution of beverages in US children by age, weight, and consumer status. Child Obes. 2015;11(4):475-83.

112. An R. Beverage consumption in relation to discretionary food intake and diet quality among US adults, 2003 to 2012. J Acad Nutr Diet. 2016:116(1):28-37.

113. Yee $A Z$, Lwin MO, Ho SS. The influence of parental practices on child promotive and preventive food consumption behaviors: a systematic review and meta-analysis. Int J Behav Nutr Phys Act. 2017;14(1):47.

114. Gerards SM, Dagnelie PC, Gubbels JS, van Buuren S, Hamers FJ, Jansen MW, et al. The effectiveness of lifestyle triple $P$ in the Netherlands: a randomized controlled trial. PLoS One. 2015:10(4):e0122240.

115. De Craemer M, De Decker E, De Bourdeaudhuij I, Vereecken C, Deforche B, Manios Y, et al. Correlates of energy balance-related behaviours in preschool children: a systematic review. Obes Rev. 2012;13(Suppl 1):13-28.

116. Vargas-Garcia EJ, Evans CEL, Prestwich A, Sykes-Muskett BJ, Hooson J, Cade JE. Interventions to reduce consumption of sugar-sweetened beverages or increase water intake: evidence from a systematic review and meta-analysis. Obes Rev. 2017;18(11):1350-63.

117. Bramer WM, Milic J, Mast F. Reviewing retrieved references for inclusion in systematic reviews using EndNote. J Med Libr Assoc. 2017:105(1):84-7.

118. Rothstein HR. Publication bias in meta-analysis prevention, assessment and adjustments. Chichester, England: Wiley; 2005.

119. Jansen E, Williams KE, Mallan KM, Nicholson JM, Daniels LA. Bidirectional associations between mothers' feeding practices and child eating behaviours. Int J Behav Nutr Phys Act. 2018;15(1):3. 
120. Ek A, Sorjonen K, Eli K, Lindberg L, Nyman J, Marcus C, et al. Associations between parental concerns about Preschoolers' weight and eating and parental feeding practices: results from analyses of the child eating behavior questionnaire, the child feeding questionnaire, and the lifestyle behavior checklist. PLoS One. 2016;11(1):e0147257.

121. Koning M, de Jong A, de Jong E, Visscher TLS, Seidell JC, Renders CM. Agreement between parent and child report of physical activity, sedentary and dietary behaviours in 9-12-year-old children and associations with children's weight status. BMC Psychol. 2018;6(1):14.

122. Hill RJ, Davies PS. The validity of self-reported energy intake as determined using the doubly labelled water technique. Br J Nutr. 2001;85(4):415-30.

123. Trabulsi J, Schoeller DA. Evaluation of dietary assessment instruments against doubly labeled water, a biomarker of habitual energy intake. Am J Physiol Endocrinol Metab. 2001;281(5):E891-9.

\section{Publisher's Note}

Springer Nature remains neutral with regard to jurisdictional claims in published maps and institutional affiliations.

Ready to submit your research? Choose BMC and benefit from:

- fast, convenient online submission

- thorough peer review by experienced researchers in your field

- rapid publication on acceptance

- support for research data, including large and complex data types

- gold Open Access which fosters wider collaboration and increased citations

- maximum visibility for your research: over $100 \mathrm{M}$ website views per year

At $B M C$, research is always in progress.

Learn more biomedcentral.com/submissions 